\title{
Controlled trial evaluation of an asthma education programme for adults
}

\author{
R Yoon, D K McKenzie, A Bauman, D A Miles
}

\begin{abstract}
Background-To improve asthma control and reduce readmission rates through increased knowledge and the development of self management skills, a brief (three hour) adult education programme was developed.

Methods-The course was designed to improve inhaler skills and to teach how to adjust drug doses according to peak flow (PEF) measurements and a treatment plan. It was evaluated in a randomised controlled trial in 76 patients admitted to hospital for asthma by using questionnaires, spirometry, and home monitoring of PEF at entry and at five and 10 months after intervention. The questionnaire provided measures of knowledge about asthma, self management behaviour appropriate to asthma control, asthma symptom frequency and severity, and psychosocial disturbance attributable to asthma.
\end{abstract}

Results-During the 10 months observation period the readmission rate for the educated group was one seventh that of the control group and attendance at accident and emergency departments also decreased. No consistent differential improvements were observed in spirometric results, average PEF, or mean daily variability of PEF. Both groups showed improvements in measures of asthma knowledge, behaviour, symptoms, and psychosocial disturbances. However, the intervention group showed a significantly greater improvement in some measures of asthma knowledge and self management skills.

Conclusion-Despite minimal effect on measures of airway function, substantial changes in illness behaviour and use of health care facilities can be achieved by a brief asthma education programme.

(Thorax 1993;48:1110-1116)

Asthma is an important public health problem in Australia and is associated with recent increases in illness and death rates. ${ }^{1}$ Patient education has been promoted as an important component of national asthma management plans in Australia, the United Kingdom, and the United States in the belief that it might improve control of asthma..$^{2-4}$ Various programmes have been developed to teach asthmatic patients about their condition and the skills of self management, particularly for children. ${ }^{56}$ There are, however, few reports of controlled trials of asthma education for adult patients.

Education programmes that contain information alone increase knowledge about asthma but have little effect on asthmatic illness. ${ }^{7-10}$ Of the controlled trials of programmes with a self management component, two reports indicated a reduction in hospital admission rates or doctor consultations, ${ }^{11} 12$ one a reduction in frequency of asthma symptoms, ${ }^{13}$ and one an improvement in compliance with treatment. ${ }^{14}$ None of these studies provided data on airway function. Published data on asthma self management programmes show that the duration of tuition varied from three to 23 hours over two to 10 sessions. There is no information on the minimal requirements of an effective intervention.

To our knowledge, no controlled trials of asthma education from Australia have been published, although an uncontrolled study showed changes in knowledge and psychosocial barriers attributable to asthma. ${ }^{15}$ Our study is a randomised, controlled trial of a brief education programme (about three hours) for patients recently discharged from hospital after a severe exacerbation of asthma. The primary objectives were to improve control of asthma and to reduce the readmission rate. The educational component emphasised self management training (inhaler use and peak flow monitoring) and patients were taught how to adjust the dosage of prophylactic drugs according to peak flow variability by using a treatment plan. Measurements of air way function were included in the evaluation.

\section{Methods}

PATIENTS

The study population comprised adults admitted to the respiratory ward at a university teaching hospital in Sydney between April 1987 and April 1989 for a severe exacerbation of asthma. The study was approved by the institutional ethics committee. Eligible patients were aged 16-65 years, were literate in English, were able to attend the education centre, and had the diagnosis of asthma confirmed by history and documented
16 February 1993

Revised version received

14 July 1993

Accepted 21 July 1993 
reversibility of airflow obstruction (at least $15 \%$ predicted). Patients were excluded if they showed signs of irreversible airways obstruction - for example, due to smokingor other significant concurrent disease(s) that might influence the outcome measures of the study.

Potential subjects were identified during their stay in hospital by one of the investigators (RY). They were informed at initial contact that they might be assigned at random into an intervention or a waiting list control group. Those who agreed to participate indicated consent and completed a baseline questionnaire. After discharge from hospital these patients were invited by letter and telephone to attend a clinic for assessment, instruction in peak flow measurement, and assignment to treatment group.

During the study period 185 eligible patients expressed interest in the education programme and completed a baseline questionnaire while in hospital. The number of eligible patients who refused to participate at first contact is unknown but estimated to be small. Some eligible patients were missed by the recruiting investigator because of admission to other wards or because the investigator was unavailable for recruitment-for example, being away on holiday.

\section{STUDY DESIGN}

The figure shows the study design. Evaluation measures were obtained for all subjects at randomisation and after a mean (SD) $5.2(1.5)$ and $10.5(2.5)$ months. At the first visit all subjects were instructed in the use of a mini-Wright peak flow meter and were shown how to record the values. Those

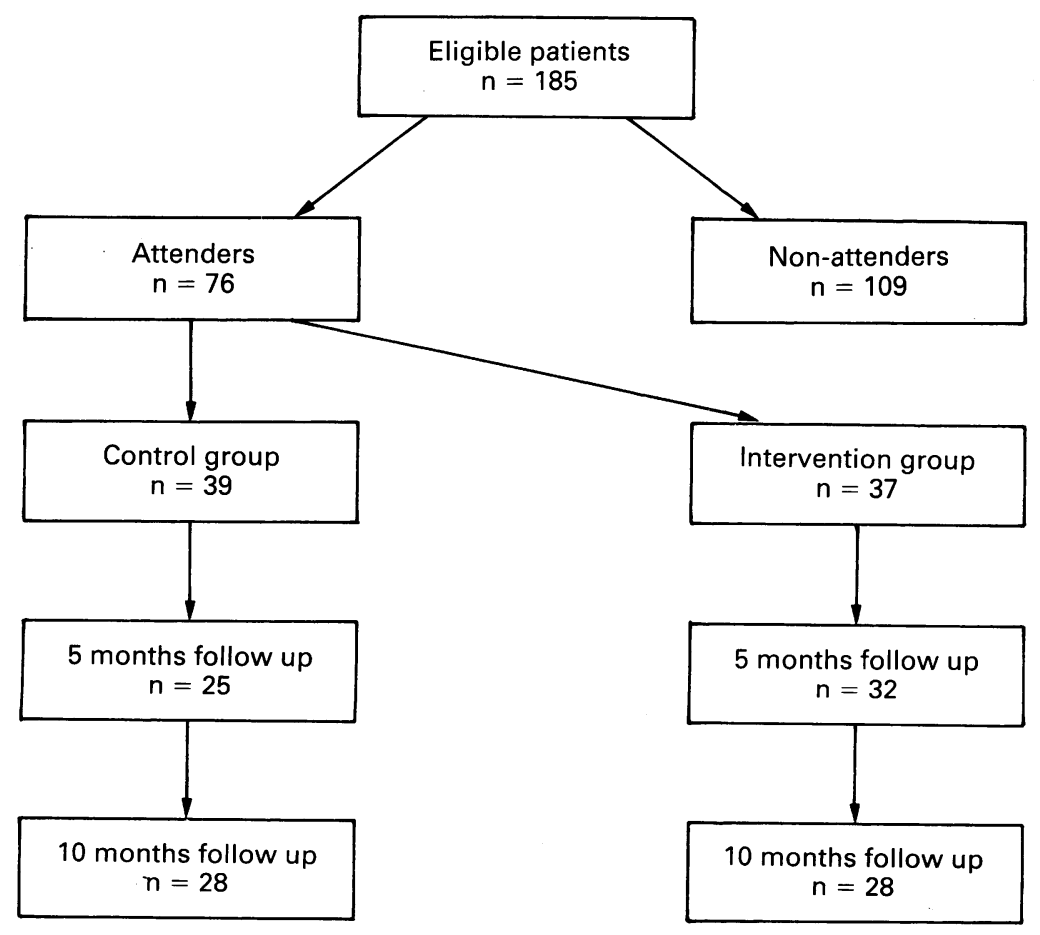

Study design. Non-attenders include subjects who attended the first assessment and were randomly allocated to the intervention or control group but did not attend intervention or any follow up assessments. who could not afford to purchase a peak flow meter were lent one. The subjects assigned to the intervention received education soon after the first visit, while the control subjects waited until after the third visit (about 12 months).

\section{OUTCOME MEASURES}

At each of the three assessments (initial, after five months, and after 10 months) subjects completed a questionnaire, had measurements of airway function, and submitted peak expiratory flow rates measured at home during the previous week.

\section{Questionnaires}

The self administered questionnaire used at baseline has been described in detail previously. ${ }^{16}$ Similar questionnaires were used at baseline and 10 months, but a slightly different version was used at five months. This was done partly to avoid test retest sensitisation. Questions about use of peak flow meters, time off work, and use of health care facilities because of asthma were included only in the baseline and final questionnaires. Briefly, the questionnaire was designed to provide measures of (a) psychosocial disturbance attributable to asthma, (b) asthma symptoms, (c) knowledge about asthma, and (d) aspects of self management behaviour appropriate to asthma control.

Psychosocial disturbance was measured by using four questions with responses scored 0-3 on a Likert scale (responses ranged from "does not apply to me" to "very much applies to me"), a high score indicating more psychosocial disturbance. Asthma symptoms were measured by using three questions about the frequency, duration, and severity of episodes of wheeze (each scored from 1-4) and a visual analogue scale ("mild to severe", scored 1-8). Knowledge was measured by using a four item multiple choice question about the changes in the lungs in asthma (adapted from Bauman et $a^{15}$ ) and a 14 item score assessing knowledge about drug treatment (based on the content of the education programme). Aspects of health beliefs about asthma were measured by using five statements; these included beliefs that drug treatment is addictive or loses effectiveness over time and that patients judge severity only by wheeze. A high score indicated desired or appropriate beliefs. In addition, there were two open ended questions on judging the severity of asthma and the use of a crisis management plan. The open ended questions were scored out of 10 by one of the investigators $(\mathrm{DMcK})$, a respiratory physician who was blinded to patients' assignment and the questionnaire number - that is, baseline, five months, and 10 months.

Airway function

Measurements of airway function were obtained with an electronic spirometer (Minato AS500). At least two acceptable maximal forced expiratory flow volume manoeuvres were performed before and after 
inhaling a $\beta$ agonist aerosol (salbutamol $400 \mu \mathrm{g}$ through a Volumatic reservoir device). The response to inhaled bronchodilator was calculated as the percentage increase in forced expiratory volume in one second $\left(\mathrm{FEV}_{1}\right)$ above the initial value. In addition, subjects recorded three values of peak expiratory flow (PEF) before and after inhaling bronchodilator in the morning and evening for one week. The best of each set of three readings was retained for subsequent analysis. The daily variability in PEF was calculated as the highest PEF minus the lowest, divided by the highest and expressed as a percentage. ${ }^{3}$ The mean of the values obtained over seven days was retained for analysis of group data.

\section{THE INTERVENTION}

The intervention was a single education session of $2 \cdot 5-3$ hours in which groups of five to eight adults learnt asthma management skills. Participants were encouraged to bring their spouses or other key people. The sessions included (a) a 40 minute interactive lecture with visual aids outlining the physiology of asthmatic airway narrowing, trigger factors (including diet and exercise), and an antismoking message; (b) a 20 minute videotape (produced by the investigators) discussing the action and side effects of asthma treatments and providing additional information on improved methods for delivery of inhaled drugs; (c) individual training in the use of peak flow meters, asthma diaries, and inhaler techniques (the range of drugs used to treat asthma and the devices used to administer them were on display); (d) a 14 minute videotape (produced by the investigators) presenting typical questions and misconceptions about asthma in a doctor-patient setting, revising peak flow measurement and correct inhaler techniques, and introducing a treatment plan; and (e) a final practical session in which patients were instructed in the use of a

Table 1 Patient characteristics at baseline. Values are numbers (percentages) of patients

\begin{tabular}{lccl}
\hline & Intervention & Control & p Value \\
\hline Sex: & $28(76)$ & $28(72)$ & NS \\
$\quad$ Female & $9(24)$ & $11(28)$ & \\
$\quad$ Male & & & \\
Past smoker: & $17(46)$ & $16(41)$ & NS \\
$\quad$ Yes & $20(54)$ & $23(59)$ & \\
$\quad$ No & & & \\
Current smoker: & $3(8)$ & $2(5)$ & NS \\
$\quad$ Yes & $34(92)$ & $37(95)$ & \\
$\quad$ No & & & \\
PFM training: & $12(32)$ & $26(67)$ & $<0.005$ \\
$\quad$ Yes & $25(68)$ & $13(33)$ & \\
$\quad$ No & & & \\
Previous AE: & $2(5)$ & $9(23)$ & $<0.05$ \\
$\quad$ Yes & $35(95)$ & $30(77)$ & \\
$\quad$ No & & & \\
Education level: & $14(38)$ & $13(33)$ & NS \\
$\quad$ School onlyt & $23(62)$ & $26(66)$ & \\
$\quad$ Post-schoolf &
\end{tabular}

$\mathrm{PFM}=$ peak flow meter; $\mathrm{AE}=$ asthma education. ^From $\chi^{2}$ statistic.

†Up to 10 years primary and secondary education.

$\ddagger$ Matriculation or tertiary training, or both. treatment plan permitting adjustment of asthma treatment according to daily peak flow variability. ${ }^{3}$

Emphasis was placed on regular maintenance treatment with inhaled corticosteroids. $\overline{\mathrm{O}}$ Patients were instructed to vary the dose $\underset{x}{\stackrel{D}{x}}$ according to the degree of symptoms or PEF variability and to seek medical attention early $\stackrel{\vec{\sim}}{\stackrel{\leftrightarrow}{\rho}}$ during severe exacerbations. They were also encouraged to use either a small spacer or a 흠 reservoir device - for example, Volumatic - $\vec{\nabla}$ especially for inhaled corticosteroids. Finally, $\varrho$ patients were provided with written informa- is tion published by the Asthma Foundation of $\overrightarrow{0}$ New South Wales.

\section{ANALYSIS}

All continuous data were normally distributed so parametric analyses were used. Between group comparisons at five and 10 months. were performed using $t$ tests for independent $\vec{\exists}$ samples. Change within individual subjects $\vec{\circ}$ was assessed by analyses of variance with 윽 adjustments for baseline values. Categorical $\rightarrow$ data were assessed by the $\chi^{2}$ statistic or the $z$ score transformation of the difference $\underset{\mathbb{D}}{ }$ between two proportions. Internal consis- $\frac{7}{8}$ tency of scores was estimated using $\mathbb{\mathbb { D }}$ Cronbach's $a$ for ordinal data and KR-20 $\vec{\bullet}$ coefficients for dichotomous data. ${ }^{17}$ These are $\stackrel{\omega}{\omega}$ standard psychometric measures of how well questionnaire items interrelate and are used in the development of summated scores. Repeatability of questionnaire measures was assessed by correlations of data based on measures two weeks apart in an independent sample of 37 adults with asthma. ${ }^{15}$

\section{Results}

Of the 185 who expressed initial interest and filled in a baseline questionnaire while in hospital, 76 completed the initial assessment and at least one of the two follow up visits (five months assessment, 57; 10 months assessment, 56; both assessments, 40). The breakdown of these numbers into intervention and control groups is shown in the figure. A comparison of baseline data between those who eventually participated in the programme (attenders, whether in the intervention group $N$ or the control group) and those who did not $\underset{\omega}{\mathrm{\omega}}$ participate after expressing initial interest $\widetilde{Z}$ (non-attenders) has been published (see also 0 discussion): $:^{16}$ The current study includes all attenders from that comparison and a number? of additional subjects recruited subsequently.

The asthma knowledge scores, psychosocial scores, and asthma symptom scores $\frac{\rho}{\mathbb{D}}$ were normally distributed. The psychosocial score was highly internally consistent (Cronbach's $a=0.86$ ) and repeatable $(r=8$ $0 \cdot 70)$. The 14 item score of knowledge about treatment was internally consistent (KR-20 = $0 \cdot 76$ ), as was the five item asthma beliefs? score $(\mathrm{KR}-20=0 \cdot 53) .^{17}$ control groups were well matched at the 
Table 2 Longitudinal analysis of use of health care facilities in intervention and control groups

\begin{tabular}{|c|c|c|c|}
\hline & $\begin{array}{l}12 \text { Months } \\
\text { before baseline }\end{array}$ & $\begin{array}{l}10 \text { Months } \\
\text { after education }\end{array}$ & p Value ${ }^{\star}$ \\
\hline \multicolumn{4}{|c|}{ No of subjects admitted to hospital: } \\
\hline Intervention & 16 & 1 & $<0.001$ \\
\hline Control & 13 & 7 & NS \\
\hline \multicolumn{4}{|c|}{ Total no of hospital admissions: } \\
\hline Intervention & 19 & 1 & $<0.001$ \\
\hline Control & 15 & 7 & NS \\
\hline \multicolumn{4}{|c|}{ No of subjects who attended A and E: } \\
\hline Intervention & 14 & 3 & $<0.01$ \\
\hline Control & 15 & 7 & NS \\
\hline \multicolumn{4}{|c|}{ Total no of attendances at $\mathrm{A}$ and $\mathrm{E}$ : } \\
\hline Intervention & 27 & 7 & $<0.001$ \\
\hline Control & 17 & 9 & NS \\
\hline \multicolumn{4}{|c|}{ Missed 2 weeks' work/school: } \\
\hline Intervention & 11 & 5 & NS \\
\hline Control & 8 & 4 & NS \\
\hline
\end{tabular}

$\mathrm{A}$ and $\mathrm{E}=$ accident and emergency department.

*Within group comparisons between two proportions (at baseline and at 10 months after education) using $\mathrm{z}$ score transformation (for numbers in each comparison see figure).

initial assessment. Most participants were young female non-smokers, a high proportion of whom had had more than 10 years of schooling. The mean age was $30(8 \cdot 8)$ years for intervention subjects and $34(13.4)$ years for the control subjects. A higher proportion of control subjects reported that they had received previous asthma education and that they had previously been shown how to use a peak flow meter. Table 2 includes some baseline indices of asthma morbidity during the 12 months before this admission. There were

Table 3 Mean (SD) raw scores from questionnaire* at baseline and 10 months after education in intervention and control groups

\begin{tabular}{|c|c|c|c|c|}
\hline & $\begin{array}{l}\text { Intervention } \\
\text { group }\end{array}$ & $\begin{array}{l}\text { Control } \\
\text { group }\end{array}$ & $F$ ratio $\nmid$ & p Value \\
\hline $\begin{array}{l}\text { Action plan (10): } \\
\text { Baseline } \\
10 \text { Months }\end{array}$ & $\begin{array}{l}2 \cdot 89(1 \cdot 61) \\
4 \cdot 79(1 \cdot 57)\end{array}$ & $\begin{array}{l}3.32(1.46) \\
3.03(1.91)\end{array}$ & $14 \cdot 37$ & $<0.001$ \\
\hline $\begin{array}{l}\text { Differentiate mild from severe atta } \\
\text { Baseline } \\
10 \text { Months }\end{array}$ & $\begin{array}{l}\text { (10): } \\
2 \cdot 18(1 \cdot 37) \\
4 \cdot 07(1 \cdot 86)\end{array}$ & $\begin{array}{l}2 \cdot 68(2 \cdot 00) \\
2 \cdot 85(2 \cdot 09)\end{array}$ & $8 \cdot 42$ & 0.005 \\
\hline $\begin{array}{l}\text { Asthma severity }(1-8): \\
\text { Baseline } \\
10 \text { Months }\end{array}$ & $\begin{array}{l}4 \cdot 65(2 \cdot 32) \\
2 \cdot 78(2 \cdot 13)\end{array}$ & $\begin{array}{l}4 \cdot 35(2 \cdot 43) \\
2 \cdot 81(2 \cdot 15)\end{array}$ & 0.35 & 0.85 \\
\hline $\begin{array}{l}\text { Symptom score }(3-12) \text { : } \\
\text { Baseline } \\
10 \text { Months }\end{array}$ & $\begin{array}{l}7 \cdot 81(2 \cdot 07) \\
5 \cdot 43(2 \cdot 50)\end{array}$ & $\begin{array}{l}7 \cdot 03(2 \cdot 50) \\
5 \cdot 67(2 \cdot 24)\end{array}$ & 0.38 & 0.54 \\
\hline $\begin{array}{l}\text { Psychosocial disturbance (12): } \\
\text { Baseline } \\
10 \text { Months }\end{array}$ & $\begin{array}{l}7 \cdot 21(4 \cdot 07) \\
4 \cdot 00(4 \cdot 38)\end{array}$ & $\begin{array}{l}6 \cdot 75(4 \cdot 65) \\
3 \cdot 96(3 \cdot 34)\end{array}$ & 0.03 & 0.87 \\
\hline $\begin{array}{l}\text { Knowledge of asthma (4): } \\
\text { Baseline } \\
10 \text { Months }\end{array}$ & $\begin{array}{l}2.89(1.02) \\
3.09(0.61)\end{array}$ & $\begin{array}{l}3.22(0.91) \\
2 \cdot 80(0.71)\end{array}$ & $3 \cdot 50$ & 0.07 \\
\hline $\begin{array}{l}\text { Asthma health beliefs (5): } \\
\text { Baseline } \\
10 \text { Months }\end{array}$ & $\begin{array}{l}1 \cdot 32(1 \cdot 10) \\
2 \cdot 46(1 \cdot 82)\end{array}$ & $\begin{array}{l}1 \cdot 68(1 \cdot 25) \\
1 \cdot 28(1 \cdot 46)\end{array}$ & $12 \cdot 21$ & $<0.001$ \\
\hline $\begin{array}{l}\text { Knowledge of asthma drugs (14): } \\
10 \text { Months }\end{array}$ & $9 \cdot 25(3.29)$ & $7 \cdot 57(2 \cdot 87)$ & $t=2 \cdot 04 \ddagger$ & $<0.05$ \\
\hline
\end{tabular}

*Maximal scores or range of possible scores in parentheses. See methods for number and type of questions used to derive each score.

†From ANOVA models assessing significance of group ${ }^{\star}$ time interaction.

$¥$ No baseline data for this score; unpaired $t$ test used in analysis.
Table 4 Mean (SD) FEV and forced vital capacity (FVC) (itres) before and after bronchodilator and before and after education in intervention and control groups

\begin{tabular}{|c|c|c|c|}
\hline $\begin{array}{l}\text { No of months } \\
\text { after education }\end{array}$ & Intervention group & Control group & p Value \\
\hline FEV $_{1}:$ & \multicolumn{2}{|l|}{ Before bronchodilator } & \\
\hline 0 & $2 \cdot 76(0.74)$ & $2.47(0.74)$ & NS \\
\hline 5 & $2.73(0.72)$ & $2 \cdot 20(0.86)$ & 0.01 \\
\hline 10 & $2.61(0.84)$ & $2.61(0.82)$ & NS \\
\hline \multicolumn{4}{|l|}{ FVC: } \\
\hline 0 & $3.66(0.89)$ & $3.51(1.04)$ & NS \\
\hline 5 & $3.71(0.94)$ & $3 \cdot 20(1.01)$ & NS \\
\hline 10 & $3.54(1.00)$ & $3 \cdot 76(1 \cdot 10)$ & NS \\
\hline $\mathrm{FEV}_{1}:$ & \multicolumn{2}{|l|}{ After bronchodilator } & \\
\hline 0 & $2.93(0.68)$ & $2.63(0.70)$ & NS \\
\hline 5 & $2.91(0.76)$ & $2.37(0.83)$ & 0.01 \\
\hline 10 & $2 \cdot 79(0.81)$ & $2 \cdot 81(0.77)$ & NS \\
\hline \multicolumn{4}{|l|}{ FVC: } \\
\hline 0 & $3.77(0.84)$ & $3.56(0.94)$ & NS \\
\hline 5 & $3.82(0.91)$ & $3.31(0.92)$ & $<0.05$ \\
\hline 10 & $3.67(0.98)$ & $3.84(1.09)$ & NS \\
\hline
\end{tabular}

no significant differences between the groups in use of health care facilities and in time off school or work as a result of asthma. Baseline knowledge and beliefs about asthma were similar, and the controls reported slightly, but non-significantly, fewer symptoms (table 3 ). There were no differences between the study groups in the use of asthma drugs. Only $43 \%$ claimed that they were using inhaled steroids before admission. The groups did not differ in baseline measures of airway function (table 4) or peak flow variability (table 5).

\section{BETWEEN AND WITHIN GROUP COMPARISON AT} FIVE AND 10 MONTHS

Tables 2 and 3 show the longitudinal comparison of two proportions-that is, the intervention versus the control group. The most striking outcome was a seven fold difference between the groups in readmission rate during the observation period (table 2). There was also a significant proportional reduction in attendances at accident and emergency departments among the intervention subjects (greater than two fold). One patient in the control group died of asthma during follow up.

Table 5 Mean (SD) PEF measurements before and after education in intervention and control groups

\begin{tabular}{|c|c|c|c|}
\hline $\begin{array}{l}\text { No of months } \\
\text { after education }\end{array}$ & $\begin{array}{l}\text { Intervention } \\
\text { group }\end{array}$ & $\begin{array}{l}\text { Control } \\
\text { group }\end{array}$ & p Value \\
\hline \multicolumn{4}{|c|}{ Average PEF $(1 / \mathrm{min})^{\star}$ : } \\
\hline 0 & $497(82)$ & $448(89)$ & $<0.05$ \\
\hline 5 & $494(87)$ & $419(80)$ & 0.005 \\
\hline 10 & $475(99)$ & $447(89)$ & NS \\
\hline \multicolumn{4}{|c|}{ Variability of PEF (\%)†: } \\
\hline 0 & $16 \cdot 4(8.9)$ & $19 \cdot 0(7 \cdot 2)$ & NS \\
\hline 5 & $15 \cdot 6(10 \cdot 2)$ & $20 \cdot 7(8 \cdot 4)$ & NS \\
\hline 10 & $20.5(11.5)$ & $19 \cdot 4(8 \cdot 4)$ & NS \\
\hline
\end{tabular}

^Individual means of the best daily values recorded over one week.

†Difference between the worst and best values each day expressed as a percentage of the best. The individual means for the week's recordings were pooled for group analysis. 
A summary of the analysis of the questionnaire data is presented in table 3. The control group had slightly better baseline scores for all variables. Both groups showed improvements at follow up in symptom scores, perception of asthma control (visual analogue scale), and in psychosocial disturbance attributable to asthma. For many of these measures there was a trend for the intervention group to show a greater proportional improvement than the controls, but few comparisons reached significance. The intervention group, however, showed a significantly greater proportional improvement compared with the control group on questions related to self management skills and some of the measures of knowledge about asthma and its treatment.

The improvements in outcome for the intervention group could not be accounted for by a greater self reported compliance with prophylactic treatments at five and 10 months. Similar proportions reported use of inhaled steroids at follow up (control $61 \%$, intervention $50 \%$ ).

\section{CHANGES IN AIRWAY FUNCTION}

Spirometric indices showed a slight decline in the control group at five months compared with the intervention group but no difference was observed between the groups at 10 months (table 4). Participants who performed lung function tests within three hours of inhaling bronchodilator showed a smaller response $\left(\mathrm{FEV}_{1}\right.$ increased by $\left.2.0 \%\right)$ than those who had not recently had treatment $(8.4 \%, p<0.005)$. However, no difference was detected in the degree of reversibility between the control and intervention groups ( $F=1.90, N S$ ) after adjustment of the lung function measurements for the recent inhalation of bronchodilator.

There was no difference between the groups in the mean variability of PEF at baseline, although the average PEF was slightly higher in the intervention group (table 5). At five months the intervention group showed no change while the control group showed increased variability. At 10 months there was no difference in variability or in average PEF. With repeat measures analysis of variance the mean PEF variability was greater in the controls $\left(\mathrm{F}_{\text {group }}=5.34, \mathrm{p}=0.02\right)$, but did not change over time $\left(F_{\text {time }}=0.46\right)$, and changes were not significantly different between the groups $\left(F_{\text {group }{ }^{\star} \text { time }}=0 \cdot 60\right)$.

\section{Discussion}

We designed and evaluated a brief, single session education programme designed to improve knowledge and self management skills of asthmatic patients admitted to hospital for a severe exacerbation of airflow obstruction. Previous brief interventions have aimed to provide information alone and the results have generally shown improvements in knowledge with no change in the rate of illness or in behaviour during illness. ${ }^{810} \mathrm{We}$ observed large changes in the use of health service facilities in association with minor differential changes in objective and subjective measures of asthma control.

Our patients all had severe asthma, given that all had an exacerbation requiring admis- $\overline{0}$ sion to hospital. Previous studies suggest that $\underset{x}{\mathfrak{D}}$ patients with severe asthma are more likely to benefit from education than are those with $\stackrel{5}{9}$ mild disease. ${ }^{5}$ Many of our patients had a $\bar{C}$ long history of asthma and might have been expected to have reasonable knowledge about asthma and its management. However, $\stackrel{\Phi}{\varrho}$ knowledge scores were generally poor at the initial assessment. About half of the sample $\vec{\circ}$ had been shown how to use a peak flow meter compared with only $5-10 \%$ of asthmatic patients in the community. ${ }^{1819}$ This suggests that those with severe disease are more likely to be advised to use a peak flow meter. Another index of severity was the high incidence of hospital admissions and visits to the emergency room in the 12 months before the $\overrightarrow{0}$ current admission. In an audit of hospital 을 management of asthma during this study we documented a relatively low use of preventive $z$ asthma drugs (inhaled steroids and sodium cromoglycate) immediately before admission $\overline{7}$ for a severe exacerbation of airway $\stackrel{\mathbb{Q}}{-}$ narrowing. ${ }^{20}$ These observations suggest that $\vec{\bullet}$ admission to hospital does not necessarily provide an educational experience. ${ }^{12}$

Our results are, in many respects, representative of adult asthmatic patients admitted to a teaching hospital. The randomisation procedure produced two groups with similar baseline demographic characteristics, severity of asthma, and patterns of previous medical treatment. Moreover, there was no difference between those who participated in the programme and a comparable number of nonparticipants in several sociodemographic and medical variables, self reported measures of asthma severity, knowledge about asthma, psychosocial disturbances, or self management behaviour. ${ }^{16}$ After adjustment for confounding factors the major determinants of attendance were whether the treating physician was enthusiastic about the programme, whether the patient was a non-smoker, and whether the patient was female. High socio- of economic status and education level were $N$ almost significant predictors.

Several factors in our study may have led 0 to an underestimation of the effect of the 0 intervention in improving outcomes. Firstly, a significantly higher proportion of control subjects reported some previous exposure to asthma education, although the nature and quantity was not assessed. This could account for the finding that control subjects scored better at baseline on many measures of knowledge. Secondly, all patients were exposed to some education as part of their routine medical treatment. They were all under the care of a respiratory physician dur- $\stackrel{P}{P}$ ing admission and $88 \%$ received specialist follow up care (physician 55\%, respiratory outpatient clinic 33\%). Moreover, most patients were instructed about their treatment by a clinical pharmacist before they were 
discharged. Thirdly, all subjects were instructed in the use of a peak flow meter and asked to chart the values for evaluation. The control subjects were not told how to interpret the values in relation to a management plan. Finally, a significantly higher proportion of control subjects were readmitted or attended an accident and emergency department during the observation period. Most of these were represcribed oral corticosteroids and showed associated improvements in airway function and symptoms at subsequent evaluations. Any or all of these factors could have contributed to the improvements in most of the outcome measures observed in the control group. The death of one control patient cannot be assessed as an outcome of the trial itself.

Many of our results are consistent with previous published reports of controlled trials of asthma education. Maiman et al reported reduced attendance at accident and emergency departments (the magnitude of which was not given) after education provided by nursing staff. ${ }^{21}$ Mayo et al reported a threefold reduction in admission rates and a twofold reduction in days spent in hospital. ${ }^{11} \mathrm{~A}$ fourfold reduction in consultations was obtained by Charlton et al. ${ }^{12}$ We found that the educated group showed a decrease in admission rates and attendances at accident and emergency departments while the control group remained relatively unchanged. A significant improvement in knowledge about asthma was confirmed for the educated group, although the control group scored better at baseline and showed improvement in some indices at subsequent evaluations. Aspects of illness behaviour were tested with open ended questions about use of a peak flow meter and management plan to control exacerbations. These questions showed the largest proportional changes and suggest that success in asthma education relies on altered behaviour rather than improved asthma control. In other words, intervention subjects may have been better able to manage or prevent acute severe exacerbations of airflow obstruction by appropriate increases in drugs. This would not necessarily be reflected in the present data obtained during remission. Both groups showed substantial reductions in psychosocial barriers due to asthma with a relatively greater change in the intervention group which failed to reach significance.

Our results show that a brief education programme aimed at improving self management skills can decrease the number of admissions to hospital and attendances at accident and emergency departments in a group of adult asthmatic patients who had been admitted. Other education programmes with comparable outcomes incorporated up to eight times the duration of education, usually in several sessions, and involved several health professionals at each session. ${ }^{22-24}$ Our programme requires few resources and is easily transportable to community health centres or other sites. With the cognitive component based on video tapes, the programme could be delivered by health educators or nurses with minimal special training.

The overall impact of asthma education will depend ultimately on the proportion of asthmatic patients attending such programmes as well as the efficacy of the intervention. We have documented a low participation rate among asthmatic patients who have recently been admitted to hospital. ${ }^{16}$ Non-participants were repeatedly approached by an enthusiastic advocate of education. Recruitment of asthmatic patients from the community through advertisements would be expected to be even less successful. ${ }^{25}$ Therefore the present results reflect the outcome of intervention in a minority of presumably well motivated patients amenable to change. The results are not generalisable to non-attenders, who include most current smokers. However, this criticism applies equally to all published data on patient education. Attempts to reduce the overall morbidity of asthma will have limited success unless a strategy can be developed to improve the self management practices of patients who do not attend education programmes. Most asthmatic patients visit a family physician occasionally, but many of these doctors are reluctant to refer patients to a hospital clinic for education. ${ }^{18}$ Thus, it may be necessary also for patient education to be provided at a community level, preferably with the active cooperation of local family physicians. We have documented that patients are more likely to attend education if their physician has an interest in the programme. ${ }^{16}$ For such a system to be maximally effective family physicians need to be aware of current concepts of optimal asthma management.

This study was supported by the Asthma Foundation of New South Wales and a health service development grant from the Commonwealth Government of Australia. We thank Associate Professor HJH Colebatch for his comments on the manuscript.

1 National Health And Medical Research Council of Australia. Asthma in Australia. Strategies for reducing morbidity and mortality. Sydney: NHMRC, 1988.

2 British Thoracic Society, Research Unit of The Royal College of British Physicians of London, National Asthma Campaign. Guidelines for management of asthma in adults, I. Chronic persistent asthma. BMF 1990;301:651-3.

3 Woolcock A, Rubinfeld AR, Seale JP, Landau LL, Antic $\mathrm{R}$, Mitchell C, et al. Asthma management plan, 1989. Med $\mathcal{F}$ Aust 1989;151:650-3.

4 Parker SR, Mellins RB, Sogn DD. NHLBI workshop summary. Asthma education: a national strategy. $A m$ Rev Respir Dis 1989;140:848-53.

5 Clark NM. Asthma self-management education. Research and implications for clinical practice. Chest 1989;95:1110-3.

6 Howland J, Bauchner H, Adair R. The impact of paediatric asthma education on morbidity. Assessing the evidence. Chest 1988;94:964-9.

7 Sly RM. Evaluation of a sound-slide program for patient education. Ann Allergy 1975;34:94-9.

8 Moldofsky H, Broder I, Davies G, Leznon A. A videotape educational program for people with asthma. Can Med Assoc F 1979;120:669-72.

9 Darr MS, Self TH, Ryan MR, Vanderbush RE, Baswell $\mathrm{RL}$. Content and retention evaluation of an audio-visual patient education program on bronchodilators. $\mathrm{Am} \mathcal{F}$ Hosp Pharm 1981;38:672-5.

10 Hilton S, Sibbald B, Anderson HR, Freeling P. 
Controlled evaluation of the effects of patient education on asthma morbidity in general practice. Lancet 1986; i: $26-9$.

11 Mayo PH, Richman J, Harris HM. Results of a program to reduce admissions for adult asthma. Ann Intern Med 1990;112:864-71.

12 Charlton I, Charlton G, Broomfield J, Murray MA. Evaluation of peak flow and symptoms only self-management plans for control of asthma in general practice. BMF 1990;301:1355-9.

13 Snyder SE, Winder JA, Creer TL. Development and evaluation of an adult asthma self-management program: wheezers anonymous. $\mathcal{F}$ Asthma 1987;24:153-8.

14 Windsor RA, Bailey WC, Richards JM, Manzella B, Soong SJ, Brooks M. Evaluation of the efficacy and cost effectiveness of health education methods to increase medication adherence among adults with asthma. $A m \mathcal{F}$ Public Health 1990;80:1519-21.

15 Bauman AE, Craig AR, Dunsmore J, Browne G, Allen $\mathrm{DH}$, Vandenberg R. Removing barriers to effective selfmanagement of asthma. Patient Education and Counselling 1989;14: 217-26.

16 Yoon R, McKenzie DK, Miles DA, Bauman A. Characteristics of attenders and non-attenders at an asthma education program. Thorax 1991;46:886-90.

17 Streiner EL, Norman GR. Health measurement scales. Oxford: Oxford University Press, 1989.
18 Bauman A, McKenzie DK, Young L, Yoon R. Asthma education: the perception of family physicians. $\mathcal{F}$ Asthma 1990;27:385-92.

19 Barritt P, Davies R. Measuring success in asthma care. Fam Pract 1986;3:229-34.

20 Yoon R, McKenzie DK. Management of acute asthma in a teaching hospital: an audit of drug utilisation prior to and during admission. Australian fournal of Hospital Pharmacy 1992;22:296-301.

21 Maiman LA, Green LW, Gibson G, MacKenzie EJ. Education for self-treatment by adult asthmatics. $\mathcal{f} A M A \mathcal{G}$ 1979;241:1919-22.

22 Staudenmayer H, Harris PS, Selner JC. Evaluation of a self-help education exercise program for asthmatic children and their parents. F Asthma 1981;18:1-5.

23 Clark NM, Feldman CH, Evans D, Levison MJ, Wasilewski Y, Mellins RB. The impact of health education on frequency and cost of health care use by low income children with asthma. $\mathcal{F}$ Allergy Clin Immunol 1986;78: 108-15.

24 Ringsberg KC, Wiklund I, Wilhelmsem L. Education of adult patients at an asthma school: effects on quality of life, knowledge and need for nursing. Eur Respir $\mathcal{F}$ 1990;3:33-7.

25 Malmgren S, Anderson G. Who were reached by and participated in a one year newspaper health information campaign? Scand $\mathcal{F}$ Soc Med 1986;14:133-40. 